\title{
Evaluation of the Korea Meteorological Administration Advanced Community Earth-System model (K-ACE)
}

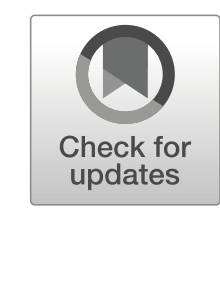

\author{
Johan Lee ${ }^{1,2} \cdot$ Jisun Kim ${ }^{1} \cdot$ Min-Ah Sun ${ }^{1} \cdot$ Byeong-Hyeon Kim ${ }^{1} \cdot$ Hyejin Moon ${ }^{1} \cdot$ Hyun Min Sung ${ }^{1}$ (I) Jinwon Kim ${ }^{1}$. \\ Young-Hwa Byun ${ }^{1}$
}

Received: 6 March 2019 / Revised: 22 July 2019 / Accepted: 25 July 2019 /Published online: 26 August 2019

(C) The Author(s) 2019

\begin{abstract}
Scientific community has been elaborating to better understand the observed climate and its variations, and to improve the capability for predicting future climate. Many modeling groups participating in the Coupled Model Inter-comparison Project (CMIP) have been working towards multi-model ensemble approach that have become a standard technique for projecting future climate and for assessing associated uncertainties to deal with intrinsic shortcomings of climate models. Within this context, the National Institute of Meteorological Sciences/Korea Meteorological Administration (NIMS/KMA) has developed the KMA Advanced Community Earth-system model (K-ACE) under KMA-Met Office collaboration for climate research. This paper provides general descriptions of the first generation K-ACE model including the coupling strategy, as well as preliminary evaluations of the model performance in mean climate fields. The first generation K-ACE model appears to capture the mean climatology and the inter-annual variability of the observed climate. Horizontal distributions and the variability of the surface and pressure-level variables agree well with observations with correlation coefficients of $0.88-0.99$ and $0.69-0.99$, respectively. Measured in terms of performance index between the observed and simulated fields, the K-ACE performance is comparable with those of 29 CMIP5 models. This study also identifies key weaknesses of the KACE in the present-day climate. Improving these deficiencies will be a topic of future studies. The NIMS/KMA will employ the K-ACE model to contribute to the CMIP6 experiment.
\end{abstract}

Keywords CMIP6 $\cdot$ K-ACE $\cdot$ Earth-system model $\cdot$ Coupled model $\cdot$ Climatology

\section{Introduction}

Climate models are an important tool in simulating the responses of the Earth's climate system to the emissions of greenhouse gases (GHGs) and atmospheric aerosols that are critical for shaping future climate. Many centers around the world are currently developing their own

Responsible Editor: Soon Il An.

Hyun Min Sung

sunghm122@korea.kr

1 Climate Research Division, National Institute of Meteorological Sciences, Seogwipo, Jeju, South Korea

2 Earth System Research Division, National Institute of Meteorological Sciences, Seogwipo, Jeju, South Korea models and are contributing to the activities of the Intergovernmental Panel on Climate Change (IPCC). Through internationally coordinated model comparison projects such as the coupled model inter-comparison project (CMIP), many modeling groups have developed coupled models including from simple conceptual ones to highly advanced ones that cover the entire Earth system. Reichler and Kim (2008) suggested that the performance of climate models has improved in each generation of the CMIP. Since the IPCC Fourth Assessment Report (hereafter AR4), a number of improvements have been introduced to climate models in their resolutions, parameterizations of various physical processes, and additional components of the Earth system. The IPCC Fifth Assessment Report (AR5) (IPCC 2014) indicates that a number of current state-of-the-art models include various components of the Earth system to result in 
significant progresses in simulating the physical, chemical, and biogeochemical components of Earth systems. Models use numerical representations of complex processes in the climate system. These representations depend on the assumptions and methods used in the model and are sources of inherent internal variability and diverse responses to external climate forcing. According to FAQ 12.1 in AR5, various numerical representations for climate models result in inter-model spreads; however, these differences are acceptable since they allow us to estimate the range of uncertainties in multi-model ensemble climate projections. The multimodel ensemble approach has become a standard technique in projecting future climate (AR5, chapter 12).

The National Institute of Meteorological Sciences/ Korea Meteorological Administration (NIMS/KMA) has been participating in CMIP experiments under the framework of the IPCC. There have been many efforts in the scientific community to assess the observed climate change, to develop measures to enhance understanding of it, and to secure the capacity for projecting future climate change. In this context, NIMS/KMA has developed the KMA Advanced Community Earth (K-ACE) model, a coupled atmosphere-ocean-land model created via KMAMet Office collaboration for climate research. This paper presents general descriptions of the K-ACE model including the coupling strategy, as well as the evaluations of the model's performance in simulating key climate fields assessed in a multi-decadal present-day simulation. The following sections provide descriptions of the model components, experimental design for the present-day experiment, and the results from their evaluations.

\section{Model Description}

The Earth System Model, as common used climate community, refers to the interacting composition of physical climate system along with the physical, biological and chemical processes (Flato 2011). The KMA's Advanced Community Earth system (K-ACE) model was developed by coupling with each component of Earth System Model which has well represented biogeochemical processes. Compositions of K-ACE are the UM (Unified Model of UK Met Office; Walters et al. 2017), MOM (Modular Ocean Model of GFDL; Griffies et al. 2007), CICE (Sea Ice model of Los Alamos; Hunke et al. 2015), and the OASIS3-MCT coupler (Craig et al. 2017; Valcke et al. 2015). Sea ice is generally known to affect the heat and moisture exchanges between the atmosphere and ocean. Our coupling approach takes this feature: sea ice model is directly coupled to the atmosphere and ocean layers and acts as an intervening layer that moderates the heat and moisture fluxes between the atmosphere and ocean. The following subsections describe the main features of each component model and of the coupler.

\subsection{Atmospheric Component}

The Unified Model (UM) in the Global Atmosphere 7.1 configuration, the latest optimal configuration for use in both weather and climate predictions (Walters et al. 2017; hereafter GA7.1), is the atmospheric component of the K-ACE model. The model solves a set of nonhydrostatic and fully compressible governing equations for atmospheric motions on a regular latitude-longitude grid nest in the horizontal and on a hybrid grid in the vertical (Wood and Mason 1993; Wood et al., 2014). The main prognostic variables include threedimensional wind, virtual dry potential temperature, and moisture variables related to water phases. The dependent variables are staggered horizontally using the Arakawa C-grid (Arakawa and Lamb 1977) and vertically using the Charney-Phillips grid (Charney and Phillips 1953).

A new dynamics scheme, the Even Newer Dynamics for General atmospheric modeling of the environment (ENDGame, Wood et al. 2014), is implemented for faster and more efficient model integrations. The scheme solves the advection equation using a semiLagrangian advection for dependent model variables. In order to ensure local conservation of key conservative quantities, the model uses a shape-conserving advection scheme, the Semi-Lagrangian Inherently Conserving and Efficient (SLICE), to advect mass and tracers. Atmospheric radiative transfer is calculated using the radiation scheme, Suite Of Community RAdiative Transfer codes based on Edwards and Slingo SOCRATES (Edwards and Slingo 1996) that features correlated-k coefficients (Rothman et al. 2013) for 81 gas species. Tropospheric aerosols are calculated using the GLObal Model of Aerosol Processes (Mann et al. 2010; Bellouin et al. 2011, 2013) that considers the number concentration, size distribution, composition, and optical properties of aerosols based on the aerosol microphysics and chemistry. Atmospheric convection is calculated using a mass-flux-based scheme that transports heat, momentum, and moisture by the sub-grid scale processes within a grid box (Gregory and Rowntree 1990) with a modified closure based on the convective available potential energy (CAPE) as in Fritsch and Chappell (1980). Shallow convections are calculated using a scheme based on the Grant method (Grant 2001) in conjunction with the convective momentum transport (CMT). 


\subsection{Ocean and Sea Ice Component}

The Modular Ocean Model (MOM) in the K-ACE model was developed at the Geophysical Fluid Dynamics Laboratory (GFDL)/ the National Oceanic and Atmospheric Administration (NOAA). It solves the hydrostatic nonBoussinesq primitive equations for the resolvable-scale processes within the ocean with sub-grid scale parameterizations (Griffies et al. 2011), and can handle multiple global orthogonal curvilinear grids; a tripolar grid is used in the K-ACE model to eliminate a polar singularity near the Arctic (Murray 1996). Prognostic variables such as ocean currents, potential temperatures, and salinity are staggered horizontally on an Arakawa-B grid.

A traditional depth-based vertical coordinate is chosen because it allows the conservation of the ocean volume. The model splits the primitive equations into a faster barotropic and a slower baroclinic mode to integrate in a time-split manner using a predictor-corrector scheme in which the time tendencies for the pressure gradient and tracer advection, lateral tracer, and velocity mixings are integrated in forward time stepping. The use of forward time stepping instead of the more traditional leap-frog scheme, makes time filtering steps (e.g., the Robert-Asselin filter) unnecessary for ensuring numerical stability, and in turn allows discrete and exact conservation of tracers. A third-order Adams-Bashforth scheme is used to advect all prognostic model variables except tracers. The multi-dimensional flux-limited scheme adapted from the global climate model from the Massachusetts Institute of Technology, is used to advect tracers to ensure monotonicity and efficiency in this configuration.

An external mode solver is used to deal with the explicit free surface of the model. The volumes of the top model grid cells are time-dependent for conservation of the fresh water budget at the atmosphere-ocean interface. In addition, the salinity flux from sea ice is used directly instead of an estimated virtual one that is proportional to the fresh water input. Neutral tracer diffusion and GentMcWilliams stirring are implemented to diffuse neutral tracers. The K-profile parameterization scheme (Large et al. 1994, 2001) is used for vertical mixing and the Smagorinsky viscosity scheme (Griffies and Hallberg 2000) with the anisotropic biharmonic operator is used for the horizontal diffusion. To diffuse tracers along topography, a sigma-diffusion (Beckmann and Döscher 1997; Döscher and Beckmann 1999) is used with enhanced diffusion for weakly stratified environments.

The Los Alamos sea ice model (CICE) version 5.1.2 (Hunke et al. 2015) in the K-ACE model was developed by the members of the community climate system model polar climate working group and by the researchers at the UK Met Office Hadley Centre. The model predicts the spatiotemporal evolution of the ice thickness distribution (ITD) (Thorndike et al. 1975). The sub-grid-scale ITD is modeled by dividing the ice pack at each grid point into several thickness categories (Bitz et al. 2001) and by calculating other physical properties such as the turbulent heat fluxes. When snowfall and the vertical conductive, radiation and turbulent fluxes are given, ice thermodynamics can compute the local growth or melting rates for the ice and snow layers. Ice dynamics determine the material strength of the ice and predict the velocity field of the ice pack. The area-conserving advection scheme is used to advect ice concentrations, volumes, enthalpies, and other state variables (Lipscomb and Hunke, 2004). The ridging parameterization for transferring ice between thickness categories, maintains the energetic balances and strain rates (Lipscomb et al. 2007).

\subsection{Land Component}

To simulate the land surface processes, the Joint UK Land Environment Simulator (JULES) in the Global Land 7.0 configuration (Walters et al. 2017; hereafter GL 7.0) has been employed. The JULES is coupled directly to the atmosphere model (UM) for calculating the surface energy balance, hydrological and carbon cycles, and soil variables in conjunction with dynamic vegetation process (Best et al. 2011). The model calculates surface temperatures on the land and sea ice surface. The carbon cycle is represented in terms of carbon fluxes, leaf and canopy photosynthesis, and stomatal conductance (Clark et al. 2011).

K-ACE uses a traditional tile approach (mosaic) widely used in land surface models (Essery et al. 2003); a total of nine plant functional types (PFTs) with five vegetated and four non-vegetated types are used to represent the sub-grid scale surface heterogeneity. Physiological parameters such as the maximum photosynthetic rate and the optimal temperature for photosynthesis are determined by land surface categorization, implying that an accurate categorization of surface type is critical for climate simulations.

Land surface types are classified using the Land Use Harmonization data v2 (LUHv2; Lawrence et al. 2016); the land cover data from the Max Planck Institute for Meteorology (Pongratz et al. 2008) are used where the former is insufficient. The soil hydrological parameters are taken from the Harmonized World Soil Database (FAO/IIASA/ ISRIC/ISS-CAS/JRC 2009). The plant canopy height is provided from the Global Soil Data Task (2000).

\subsection{Coupling the Components}

The K-ACE model is coupled using the OASIS3-MCT coupler (Valcke et al. 2013, 2015) which has advanced features for improved parallelization and coupling of high resolution and multivariate exchanges (Craig et al. 2017). While the atmospheric model uses a regular latitude-longitude grid, the ocean 
Table 1 Variables from the atmosphere coupled to the sea ice

\begin{tabular}{lll}
\hline Variable & Description & Unit \\
\hline$\left\langle M_{t(n)}^{a}\right\rangle$ & Sea ice top melting flux & $\mathrm{W} \mathrm{m}^{-2}$ \\
$\left\langle M_{b(n)}^{a}\right\rangle$ & Sea ice bottom melting flux & $\mathrm{W} \mathrm{m}^{-2}$ \\
$\left\langle q_{\text {sub(n) }}^{a}\right\rangle$ & Sublimation rate & $\mathrm{kg} \mathrm{m}^{-2} \mathrm{~s}^{-1}$ \\
$T_{i s(n)}^{a}$ & Sea ice skin temperature & $\mathrm{K}$ \\
$\left\langle F_{h}^{a}\right\rangle$ & Heat flux & $\mathrm{W} \mathrm{m}^{-2}$ \\
$\left\langle F_{\text {sw }}^{a}\right\rangle$ & Shortwave flux & $\mathrm{W} \mathrm{m}^{-2}$ \\
$\left\langle q_{\text {evap }}^{a}\right\rangle$ & Evaporation over the sea & $\mathrm{kg} \mathrm{m}^{-2} \mathrm{~s}^{-1}$ \\
$\left\langle q_{\text {rain }}^{a}\right\rangle$ & Rainfall rate & $\mathrm{kg} \mathrm{m}^{-2} \mathrm{~s}^{-1}$ \\
$\left\langle q_{\text {snow }}^{a}\right\rangle$ & Snowfall rate & $\mathrm{kg} \mathrm{m}^{-2} \mathrm{~s}^{-1}$ \\
$\left\langle q_{\text {roff }}^{a}\right\rangle$ & Runoff & $\mathrm{kg} \mathrm{m}^{-2} \mathrm{~s}^{-1}$ \\
$\left\langle q_{i s n}^{a}\right\rangle$ & Ice sheet mass over Greenland & $\mathrm{kg} \mathrm{m}^{-2} \mathrm{~s}^{-1}$ \\
$\left\langle q_{i s s}^{a}\right\rangle$ & Ice sheet mass over Antarctica & $\mathrm{kg} \mathrm{m}^{-2} \mathrm{~s}^{-1}$ \\
$\left\langle\tau_{a, x}^{a}\right\rangle$ & x-component of wind stress & $\mathrm{N} \mathrm{m}^{-2}$ \\
$\left\langle\tau_{a, y}^{a}\right\rangle$ & y-component of wind stress & $\mathrm{N} \mathrm{m}^{-2}$ \\
$\left\langle P_{m s l}^{a}\right\rangle$ & Sea level pressure & $\mathrm{Pa}^{a}$ \\
\hline
\end{tabular}

and sea ice models use a tripolar grid. For long-term simulations, these models are coupled using a Spherical Coordinate Remapping and Interpolation Package (SCRIP) conservative remapping method so that heat and freshwater can be exchanged in a conserving manner (Hewitt et al. 2011). The sea ice model is in the center of coupling structure (only for ocean grids), acting as an intervening layer between the atmosphere and ocean. The sea ice model receives all of the coupling fields (Tables 1, 2 for the atmosphere and the ocean models, respectively) from the atmosphere and the ocean models to update the fields with the latest state of the ice. The updated variables are then used to integrate the ice model. The updated states are returned to the atmosphere and the ocean models for the next time integration. Refer to Fig. 1, for the coupling structure. The superscript "a" denotes a variable defined on the atmospheric model grid, and the variables without a superscript denote
Table 2 Variables from the ocean coupled to the sea ice

\begin{tabular}{lll}
\hline Variable & Description & Unit \\
\hline$\left\langle T_{s s}\right\rangle$ & Sea surface temperature & $\mathrm{K}$ \\
$\left\langle S_{s s}\right\rangle$ & Sea surface salinity & $\mathrm{PSU}$ \\
$\left\langle u_{o c n}\right\rangle$ & x-component of ocean current & $\mathrm{m} \mathrm{s}^{-1}$ \\
$\left\langle v_{o c n}\right\rangle$ & y-component of ocean current & $\mathrm{m} \mathrm{s}^{-1}$ \\
$\left\langle\Phi_{f r z}\right\rangle$ & Frazil potential & $\mathrm{J} \mathrm{m}^{-2}$ \\
$\left\langle T_{f r z}\right\rangle$ & Freezing temperature & $\mathrm{K}$ \\
$\left\langle H_{s s}\right\rangle$ & Sea surface height & $\mathrm{m}$ \\
\hline
\end{tabular}

variables defined on either the ocean or the sea ice grids; of these, the horizontal grids are identical in the coupling system. The subscript " $n$ " with the parenthesis denotes the sea ice depth category. The angled brackets denote a grid box mean value; otherwise, the latter is local or averaged only over the sea ice.

For the exchanges between the atmosphere and the sea ice models, the atmosphere and sea ice models utilize different grids, and thus model variables are transformed from one grid to the other grid using conservative or bilinear interpolation methods. All the scalar variables except wind stress are interpolated using a conservative remapping which conserves the global total the variable. The wind stress is remapped using the bilinear interpolation as it is not a critical quantity for the conservation of heat and moisture in a coupled system. The exchange frequency is set to three hours, so all variables are in three-hour averages.

The coupling variables from the ice to the atmosphere and ocean are listed in Tables 3 and 4, respectively. During integrations, the sea ice model computes and updates the ice state, and passes all coupling variables to the ocean model after updating them with the recently updated sea ice state. The equation for heat flux to the ocean is similar to the equation for the surface heat budget used to determine SST: the shortwave radiation and

\section{UM (atmosphere) CICE (sea ice) MOM (ocean)}

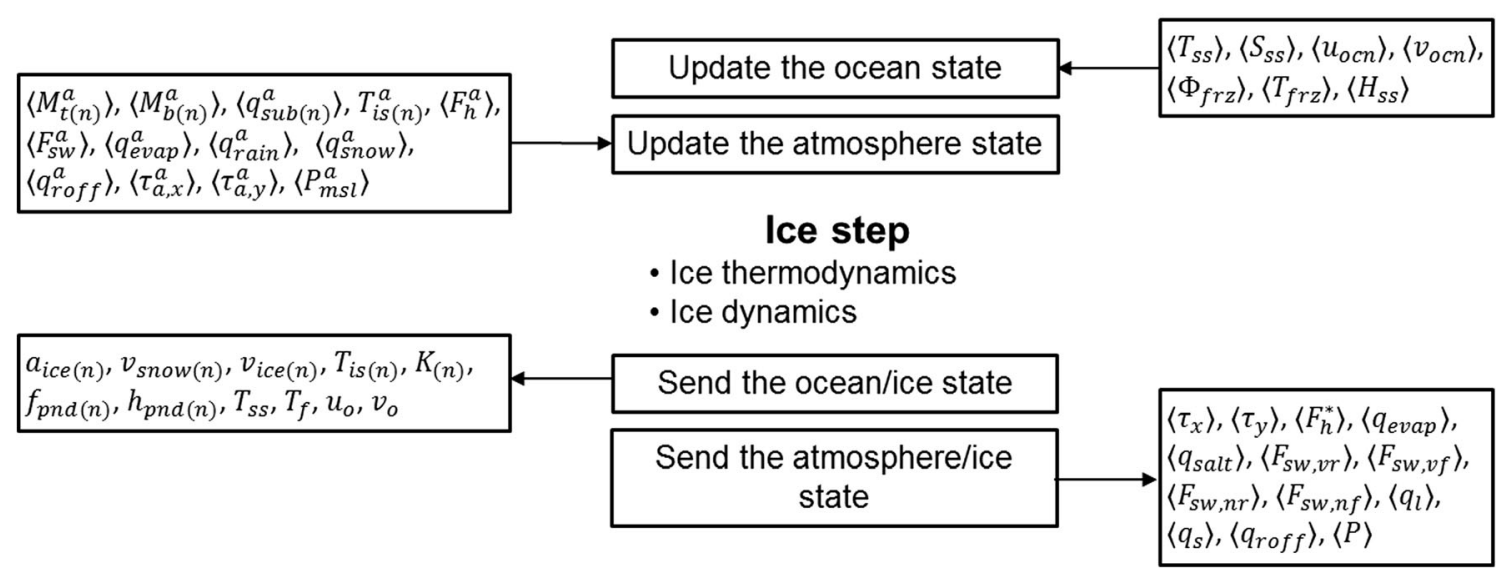

Fig. 1 Flow chart of simplified coupling process of K-ACE 
Table 3 Variables from the sea ice coupled to the atmosphere

\begin{tabular}{lll}
\hline Variable & Description & Unit \\
\hline$a_{\text {ice }(n)}$ & Sea ice fraction & - \\
$v_{\text {snow }(n)}$ & Snow volume & $\mathrm{m}$ \\
$v_{\text {ice }(n)}$ & Ice volume & $\mathrm{m}$ \\
$T_{i s(n)}$ & Sea ice surface skin temperature & $\mathrm{K}$ \\
$K_{(n)}$ & Sea ice top layer conductivity & $\mathrm{W} \mathrm{m}{ }^{-1} \mathrm{~K}^{-1}$ \\
$f_{\text {pnd }(n)}$ & Melt pond fraction & - \\
$h_{p n d(n)}$ & Melt pond depth & $\mathrm{m}$ \\
$T_{S S}$ & Sea surface temperature & $\mathrm{K}$ \\
$T_{f}$ & Freezing temperature & $\mathrm{K}$ \\
$u_{o}$ & X-component of the ocean current & $\mathrm{m} \mathrm{s}^{-1}$ \\
$v_{o}$ & y-component of the ocean current & $\mathrm{m} \mathrm{s}^{-1}$ \\
\hline
\end{tabular}

snowfall are added to the terms from the atmosphere with the updated ice state. The additional subscripts for shortwave radiation denote visible direct ( $v r)$, visible diffusive $(v f)$, near infrared (IR) direct $(n r)$, and near IR diffusive (nf) components (Table 4); these are necessary because the sea ice model partitions shortwave radiation into its constituent components using empirical weights. The two visible components are used for penetrative ocean heating and biogeochemistry, and the selection of the empirical weights affect the ocean vertical structure and circulation. The calving, or frozen runoff, is not considered yet but is reserved for future analysis.

However, the momentum, freshwater, and heat fluxes exchanges from the atmosphere to the ocean are directly coupled in outside of sea ice area. The component of heat exchanges (turbulent fluxes) provided from the atmosphere is coupling interval time-mean values. Also, the component of rain, snow and river input provide freshwater to the ocean and evaporation take freshwater away from the ocean (Hewitt., et al. 2011).

Table 4 Variables from the sea ice coupled to the ocean

\begin{tabular}{lll}
\hline Variable & Description & Unit \\
\hline$\left\langle\tau_{x}\right\rangle$ & x-component of stress on ocean & $\mathrm{N} \mathrm{m}^{-2}$ \\
$\left\langle\tau_{y}\right\rangle$ & y-component of stress on ocean & $\mathrm{N} \mathrm{m}^{-2}$ \\
$\left\langle F_{h}^{*}\right\rangle$ & Heat flux & $\mathrm{W} \mathrm{m}^{-2}$ \\
$\left\langle q_{\text {evap }}\right\rangle$ & Evaporation over the sea & $\mathrm{kg} \mathrm{m}^{-2} \mathrm{~s}^{-1}$ \\
$\left\langle q_{\text {salt }}\right\rangle$ & Salt flux into the ocean & $\mathrm{kg} \mathrm{m}^{-2} \mathrm{~s}^{-1}$ \\
$\left\langle F_{s w, v r}\right\rangle$ & Shortwave radiation, visible direct & $\mathrm{W} \mathrm{m}^{-2}$ \\
$\left\langle F_{s w, v f}\right\rangle$ & Shortwave radiation, visible diffusive & $\mathrm{W} \mathrm{m}^{-2}$ \\
$\left\langle F_{s w, n r}\right\rangle$ & Shortwave radiation, near IR direct & $\mathrm{W} \mathrm{m}^{-2}$ \\
$\left\langle F_{s w, n f}\right\rangle$ & Shortwave radiation, near IR diffusive & $\mathrm{W} \mathrm{m}^{-2}$ \\
$\left\langle q_{l}\right\rangle$ & Liquid water flux into the ocean & $\mathrm{kg} \mathrm{m}^{-2} \mathrm{~s}^{-1}$ \\
$\left\langle q_{s}\right\rangle$ & Frozen water flux into the ocean & $\mathrm{kg} \mathrm{m}^{-2} \mathrm{~s}^{-1}$ \\
$\left\langle q_{r o f f}\right\rangle$ & Liquid runoff & $\mathrm{kg} \mathrm{m}^{-2} \mathrm{~s}^{-1}$ \\
$\langle P\rangle$ & Pressure on the water surface & $\mathrm{Pa}^{-1}$ \\
\hline
\end{tabular}

\section{Experimental Design}

To evaluate the performance of the coupled K-ACE model, focus on coupling performances in mean climatology, with a $\mathrm{K}$-ACE model simulation was performed using the presentday climatological forcing. The K-ACE results are then compared against suitable observations and CMIP5 model outputs for evaluating the absolute errors and the performance of $\mathrm{K}$ ACE relative to the CMIP5 models, respectively, in simulating key Earth system fields. For the initialization of this experiment, a two-step strategy is adopted to achieve model equilibrium. First, the atmospheric initial state is based on the initial estimate of equilibrium states from a CMIP6 pre-industrial simulation using Met Office Unified Model (thousand year of model time for spin-up). Also, the ocean component is initialized using a standard practice of the Coordinated Ocean-ice Reference Experiments (COREs) phase 2 which is useful design of the baseline experiment set for more comprehensive model or research program (Griffies et al. 2009).

In the second step (spin-up), the coupled model is forced with fixed external forcing specified for the present-day period. The ocean circulation takes thousands of years of model time to reach its equilibrium state in a coupled system; however, the upper several hundred meters of the ocean may approach to an equilibrium state within several decades with fixed forcing. Based on this hypothesis, the present-day experiment was performed for 80 years: the first 60 -year integration was for a spin-up, and the subsequent 20-year integration was used for the model evaluation in this study. In 80-year integration, the final trend of surface air temperature is less than $0.04 \mathrm{~K} /$ century and energy budget trend at the top of the atmosphere (TOA) is $-0.30 \mathrm{Wm}^{-2} /$ century (not shown). It means that the $\mathrm{K}$ ACE shows a small positive imbalance in present-day experiment. However, this trend rates may be modest in comparison with CMIP3 models, where the mediantrend is approximately $0.12 \mathrm{~K} /$ century (Sen Gupta et al. 2012), to evaluate mean climate state from KACE simulation.

For the external forcing specified from present-day mean climatology, 11-year mean forcing from 1999 to 2009 obtained by averaging the anthropogenic and natural climatological factors such as the greenhouse gases, aerosols, vegetation fractions, volcanic optical thickness, solar variability, and ozone concentration using input4MIP in CMIP6 (Meinshausen et al. 2017) was used to assess only the climatology and intrinsic variability. Meinshausen et al. (2017) suggests that the models handle only some portions of the entire GHG fraction, thus modifying the concentrations of the top five gases that the net radiative effect is equivalent to all of the GHGs. In this experiment, the concentrations of $\mathrm{CO}_{2}, \mathrm{CH}_{4}, \mathrm{~N}_{2} \mathrm{O}, \mathrm{CFC}-12$, and HFC-134a equivalent are set 
to $376.021 \mathrm{ppm}, 1783.63 \mathrm{ppb}, 318.139 \mathrm{ppb}, 1052.68 \mathrm{ppt}$, and $137.315 \mathrm{ppt}$, respectively. The concentrations are converted into mass mixing ratios before use because the model only accepts GHGs in that format.

\section{Results}

\subsection{General Model Performance}

\subsubsection{Energy Budget at the Top of the Atmosphere}

The radiation budget of the Earth is fundamental for the changes and maintenance of the climate system. The global radiative fluxes at the TOA and the surface are estimated. Figure 2 presents the annual-mean distribution of the absorbed solar radiation (ASR), outgoing longwave radiation (OLR), and net downward radiation at the TOA for the 10 -year period 2001-2010. Because of the short period of the observed data, the 20-year model climatology is compared against the 10year observational climatology. The ASR is calculated as the incoming shortwave radiation minus the outgoing shortwave radiation, and the net downward radiation is the difference between the ASR and OLR. The observations came from the Clouds and the Earth's Radiant Energy System (CERES) Energy Balanced and Filled (EBAF) Edition4A data set for the period from 2001 to 2010 (Smith et al. 2004; Loeb et al. 2009). The zonal pattern of the bias is similar to those found in Raschke et al. (2005) and Mlynczak et al. (2011). The highest ASR is over the equatorial Pacific Ocean as in the observations, and is mainly due to low ocean albedo. There are large positive biases in the ASR over the coastal waters of Peru and in the Southern Hemisphere high latitudes. The OLR is generally underestimated (overestimated) in the high (low). Overall, the net down energy is overestimated and shows a somewhat large bias in the areas where the ASR biases are large and positive.

The simulated global annual mean of net radiation at the TOA and the CERES data are 1.5 and $0.8 \mathrm{~W} \mathrm{~m}^{-2}$, respectively (Table 5). Although the difference is not trivial, considering the uncertainties in the observations as well as the reanalysis of Trenberth et al. (2009), the energy balance of the model can be considered reasonably close to the observed value.

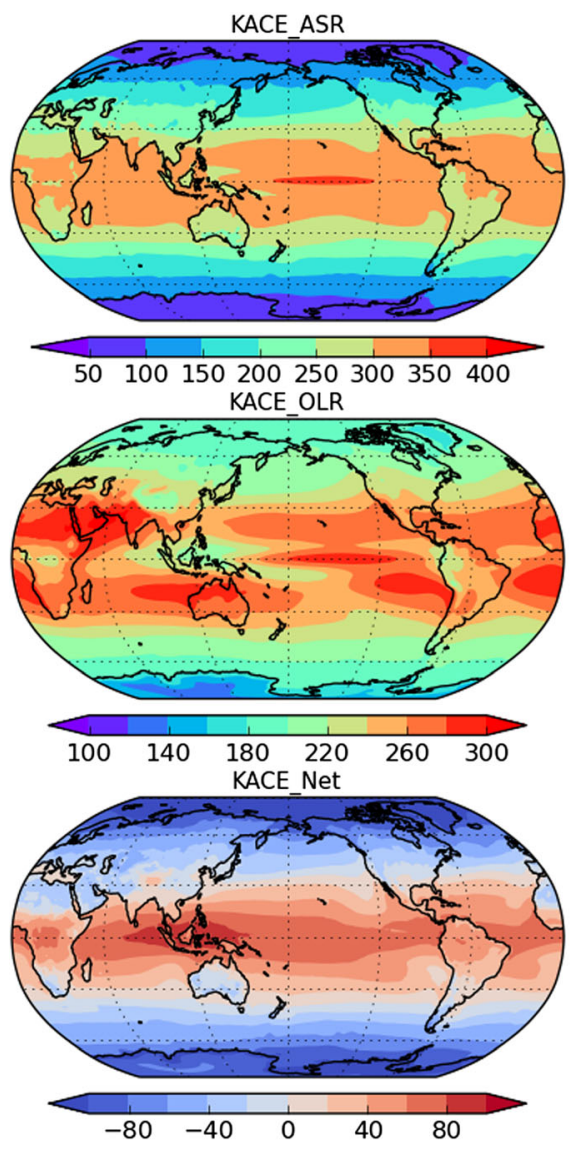

Fig. 2 Annual-mean distribution (Unit: $\mathrm{W} \mathrm{m}^{-2}$ ) of the ASR (Absorbed Solar Radiation: upper panels), OLR (Outgoing Longwave Radiation: central panels), and net down radiation (lower panels) at the TOA for

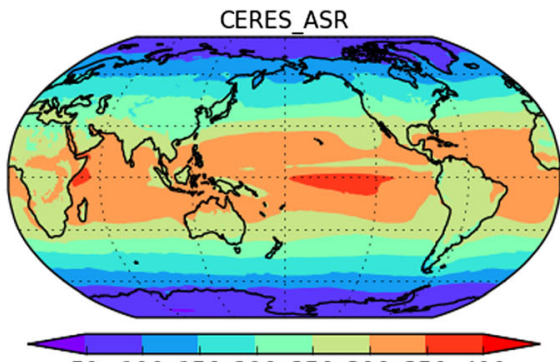

$50 \quad 100150200250300350 \quad 400$ CERES_OLR
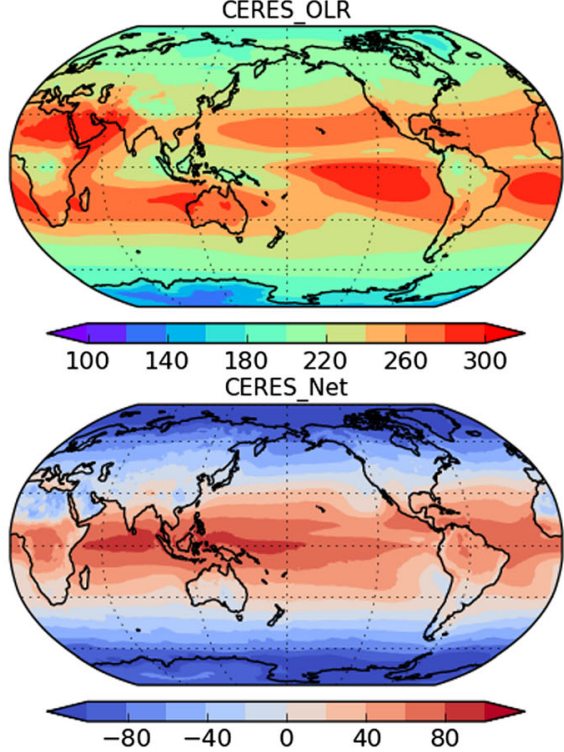

the period 2001 to 2010. Each column indicates the result of K-ACE (left), CERES (center), and bias (right)
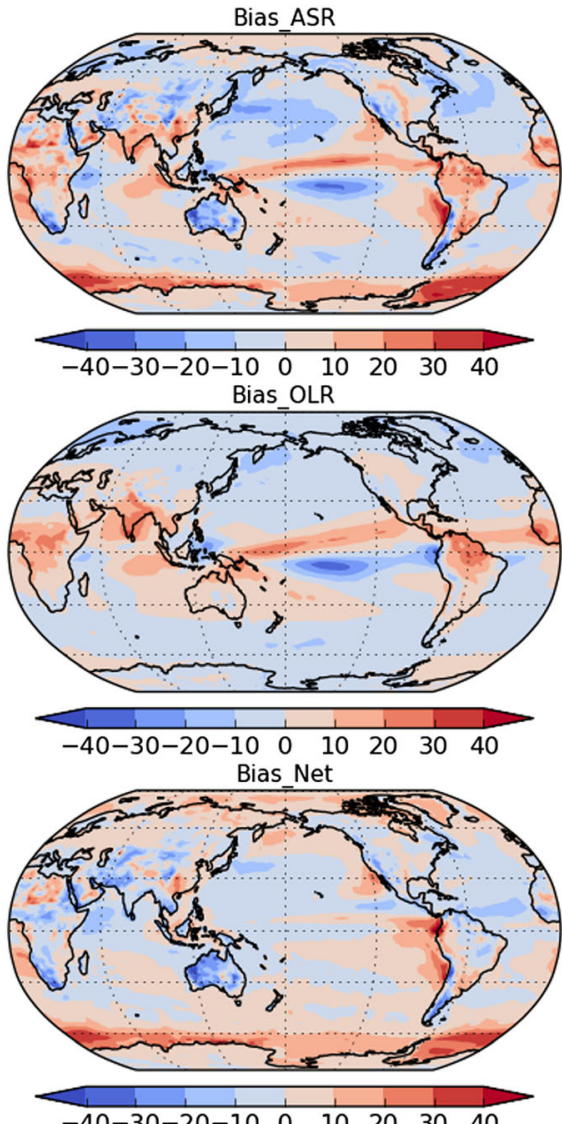
Table 5 The global annual-mean radiation budget quantities at the TOA $\left(\mathrm{Wm}^{-2}\right)$. The quantities were calculated for the downward (Solar in), reflected (Solar reflected), and absorbed solar radiations (ASR), outgoing longwave radiation (OLR), and net down radiation (Net)

\begin{tabular}{llllll}
\hline & Solar in & Solar reflected & ASR & OLR & Net \\
\hline K-ACE & 340.4 & 98.5 & 241.9 & 240.4 & 1.5 \\
CERES & 340.3 & 99.3 & 241.0 & 240.2 & 0.8 \\
\hline
\end{tabular}

However, the simulated Earth's energy imbalance at the TOA is nearly outside the range of the observed global imbalances (Hansen et al. 2005).

\subsubsection{Sea Ice Concentration}

Sea ice, a product of interactions between the atmosphere and the ocean, controls the transfer of energy, mass, and momentum between these components. As noted in AR4, the primary sources of the biases in the simulated sea ice distributions include the biases in the SST, ocean heat advection, high-

\section{Arctic sea ice concentration (DJF)}
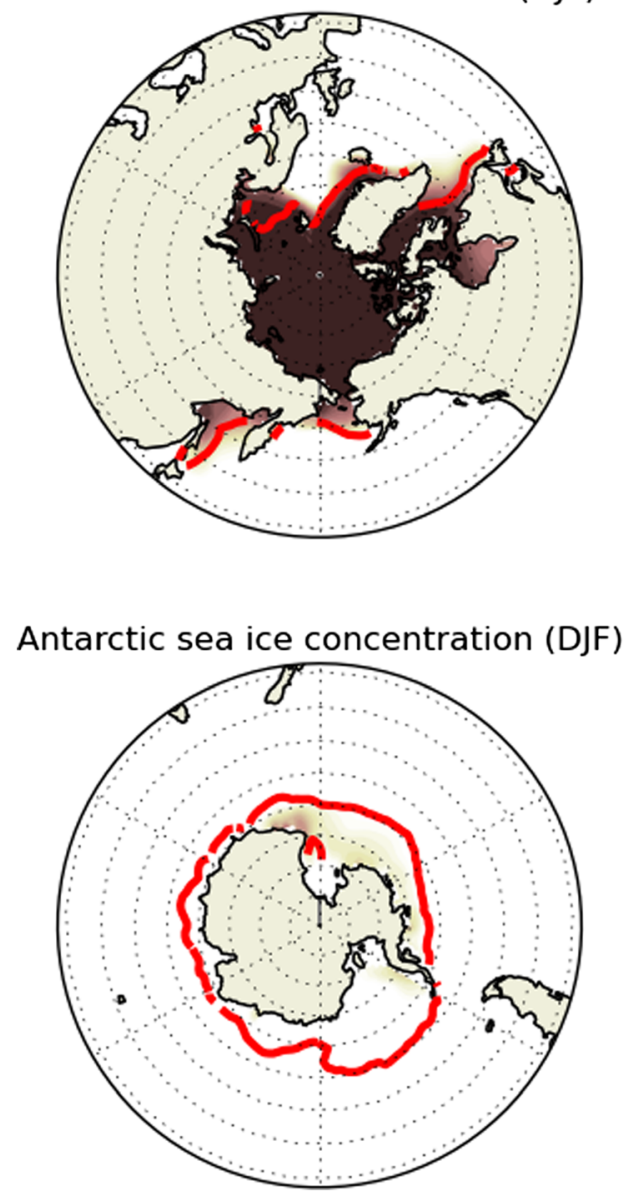

Fig. 3 Averaged sea ice concentrations (\%) in the Northern Hemisphere (upper panels) and Southern Hemisphere (lower panels) during summer (left) and winter (right) in the K-ACE 20-year simulation. The red lines latitude winds, and solar energy. Evaluating the performance of the sea ice model requires accurate data on the ice concentration, velocity, snow cover, salinity, thickness, and other factors that are difficult to obtain at this time.

Arctic and Antarctic sea ice cover from the K-ACE and observations (more than 15\%) is shown in Fig. 3. Observations are from the Hadley Centre Sea Ice and Sea Surface Temperature (HadISST) data set (Rayner et al. 2003). The bias in the simulated sea ice distribution is characterized by overestimation and underestimation of the sea ice cover in the Arctic and the Antarctic oceans, respectively, in their corresponding winter season (DJF for the Arctic and JJA for the Antarctic). Although the underestimation in the Antarctic ocean is also common in the CMIP5 models (Turner et al. 2013), the biases in the K-ACE simulation is very large; one possible cause is that the sea ice shelf flux around the Antarctica and the melting of icebergs are not considered in this sea ice model version. These two physical processes would contribute to reduce the sea surface temperature and vertical stratification of the Antarctic ocean, and eventually contribute to the increase of the Antarctic sea ice

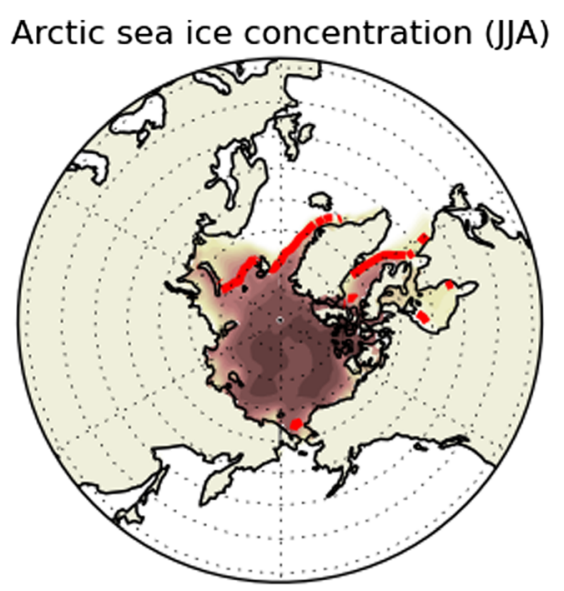

55
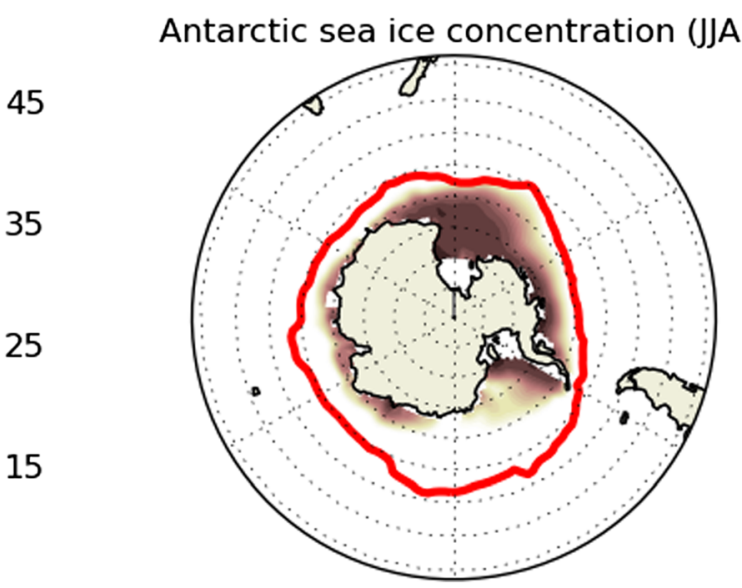

indicate observed sea ice concentrations from HadISST data which is based on $15 \%$ concentration boundaries for the period 1996 to 2015 
(Storkey et al. 2018). A parameterization including these effects is currently under development and is expected to be implemented in near future.

\subsection{Atmospheric and Surface Climatology}

A number of observation data sets are used in this study to evaluate the simulated surface climatology. The Climatic Research Unit TS 2.3 (CRU ts 3.23) analysis data (Harris et al. 2014) are employed to evaluate the simulated surface air temperature. The Global Precipitation Climatology Project (GPCP) data (Adler et al. 2003) and the ERA-Interim MSLP data (Dee et al. 2011) are used to compare the simulated precipitation and the mean sea-level pressure, respectively. For each data field, a 20-year (1996 to 2015) mean value is used as the climatology for the present-day period.

\subsubsection{Surface Air Temperature}

Temperature is determined by the amount of solar radiation affected by clouds, surface heat flux, and energy transported by the atmosphere and oceans (IPCC 2014), making it one of the key variables for measuring overall model performance. The Taylor diagram (Taylor 2001) shows that the simulated spatial distribution of the temperature climatology compares well with observations with correlation of 0.99 and standardized deviation of 1.05 (Fig. 4).

The first row in Fig. 5 shows the 20-year averaged observed and simulated surface air temperatures with their biases compared to the CRU data set from 1996 to 2015. The spatial distribution simulated by the K-ACE compares well with the observations. In most regions, the simulated and observed temperatures agree within $3 \mathrm{~K}$. Notable warm biases occur in northern Russia, northern India, central Africa, North America, South America, and Australia. The simulation also overestimates temperatures along the Pacific coastal area of the South America. There are noticeable cold biases in the Greenland and in northern Europe as well as in high elevation regions including major mountain ranges (the Rockies, the Andes, and the Alps) and the Tibetan plateau. The large biases appear mainly where the terrain slopes are large. The large biases might be due to the resolution of the model not being high enough to resolve the actual terrain within the model; this is also common in the CMIP5 models (IPCC 2014).

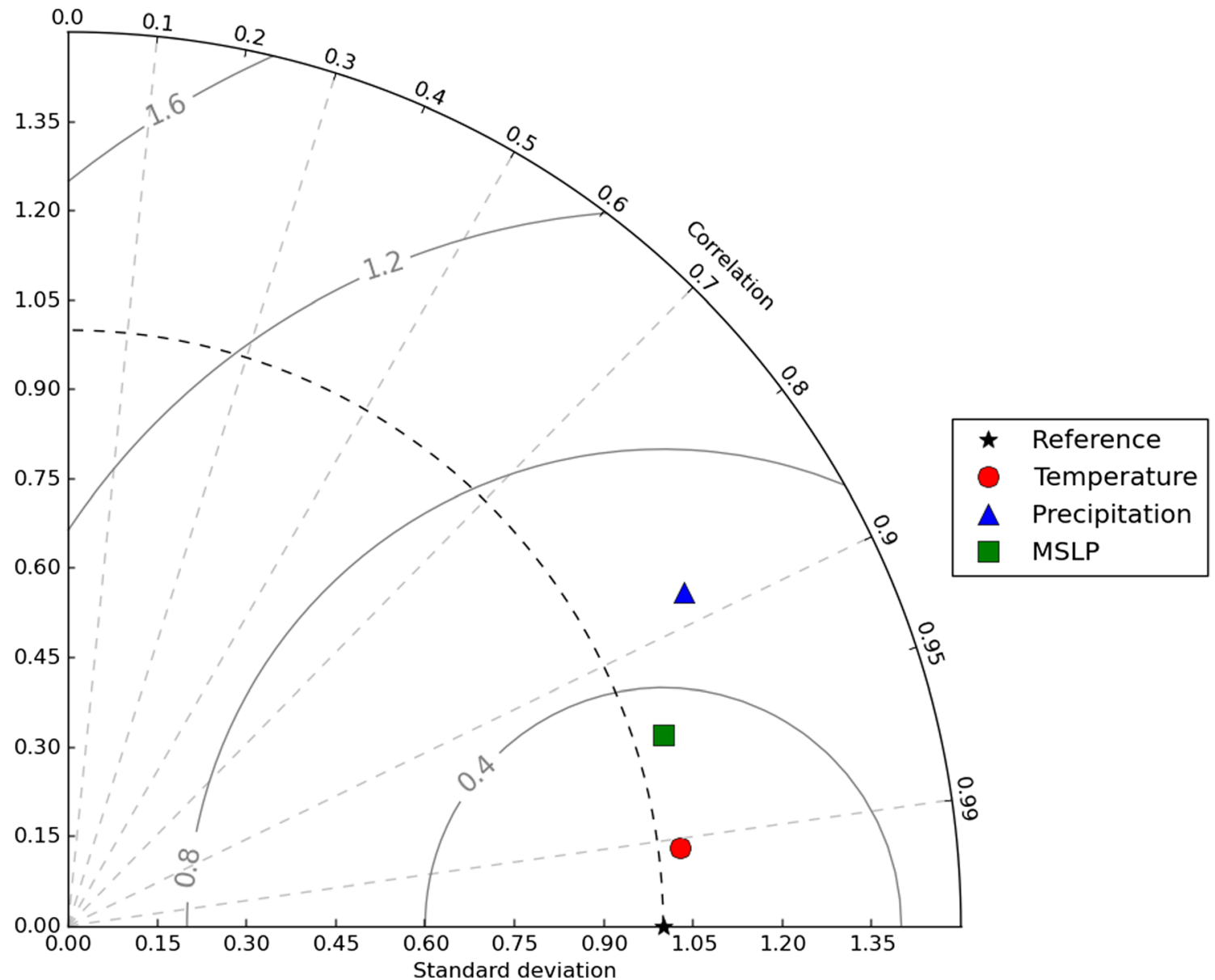

Fig. 4 Taylor diagram of the 20-year (1996-2015) surface climatology. Red/Blue/ Green markers represent the simulation field (surface air temperature, precipitation, and MSLP) evaluated against the observation data set which defined in Section 4.2. Black marker indicates the reference 


\subsubsection{Precipitation}

The lower panel of Fig. 5 shows the observed (GPCP) and simulated annual-mean precipitation, with the biases (simulation - GPCP) for the same period. The model simulates the observed large-scale zonal distribution but notably overestimates precipitation in some tropical/subtropical regions including the western North Pacific, the Maritime Continent, the South Pacific Convergence Zone, and the western Indian Ocean with dry biases in most of Europe, eastern India, off the coast of the Central America, and the Amazon basin. The South Pacific Convergence Zone (SPCZ) extends too much to the east, resulting in a double inter-tropical convergence zone (ITCZ). The dry biases over the ocean area in the eastern Pacific and the eastern Atlantic coincide with the regions of significant upwelling. The general overestimation of precipitation over the Indo-Pacific warm-pool areas is broken by the underestimation over the latitudes covering much of the Indian monsoon region, from the Equator to the Himalayas, including the eastern Indian Ocean, Bay of Bengal, and most of India. The strong dry bias in the northeastern Brazil (the Amazon basin) occurs in the region strongly affected by the tropical monsoon. The model reproduces the observed precipitation pattern over land surfaces (the upper row in Fig. 5) in the Northern Hemisphere reasonably well (also shown in Fig. 4. with pattern correlation of 0.88 and standardized deviation of 1.18).

\subsubsection{Pressure-Level Variables}

The simulated mean sea-level pressure (MSLP) also shows good agreements with observations; the pattern correlation exceeds 0.95 with standardized deviation of 1.05 (Fig. 4.). All of the pressure-level variables except on the $850 \mathrm{hPa}$ level (v850hPa, t850 hPa, and gph850hPa) show pattern correlations greater than 0.9 and standardized deviations close to unity (Fig. 6.). For the $850 \mathrm{hPa}$ fields, the correlations vary widely depending on the variables from 0.69 to 0.95 . The zonal wind (u) variations are especially well simulated with standardized deviation close to unity and correlation of 0.95 . At the 500 and $200 \mathrm{hPa}$ levels, the pattern correlations between the simulated and observed fields exceed 0.9 ( $>0.99$ for the geopotential height and temperature) with standardized deviations close to 1 except for the $200 \mathrm{hPa}$ temperatures for which standardized deviation is 1.6, much larger than for the other variables.

\subsubsection{Sea Surface Temperature}

Figure 7 compares 20-year averaged HadISST (left) and the simulated climatological SST (center); the model biases (right) are also presented. The simulated SST distribution compares well with the observations, although large biases are found in several regions. Cold biases occur over most of the Northern Hemisphere oceans, especially near the Barents and Labrador Seas and the Atlantic subtropical gyre in the North Atlantic. The model also underestimates the observed SST in the Central Pacific and in the Sea of Okhotsk. There are warm biases most notable off the Pacific coast of Japan where the Kuroshio Current exists and in the western North Atlantic. Positive SST biases are also clear in and near the strong upwelling region of western tropical Africa and the tropical eastern Pacific off the coast of Peru. These biases are a common
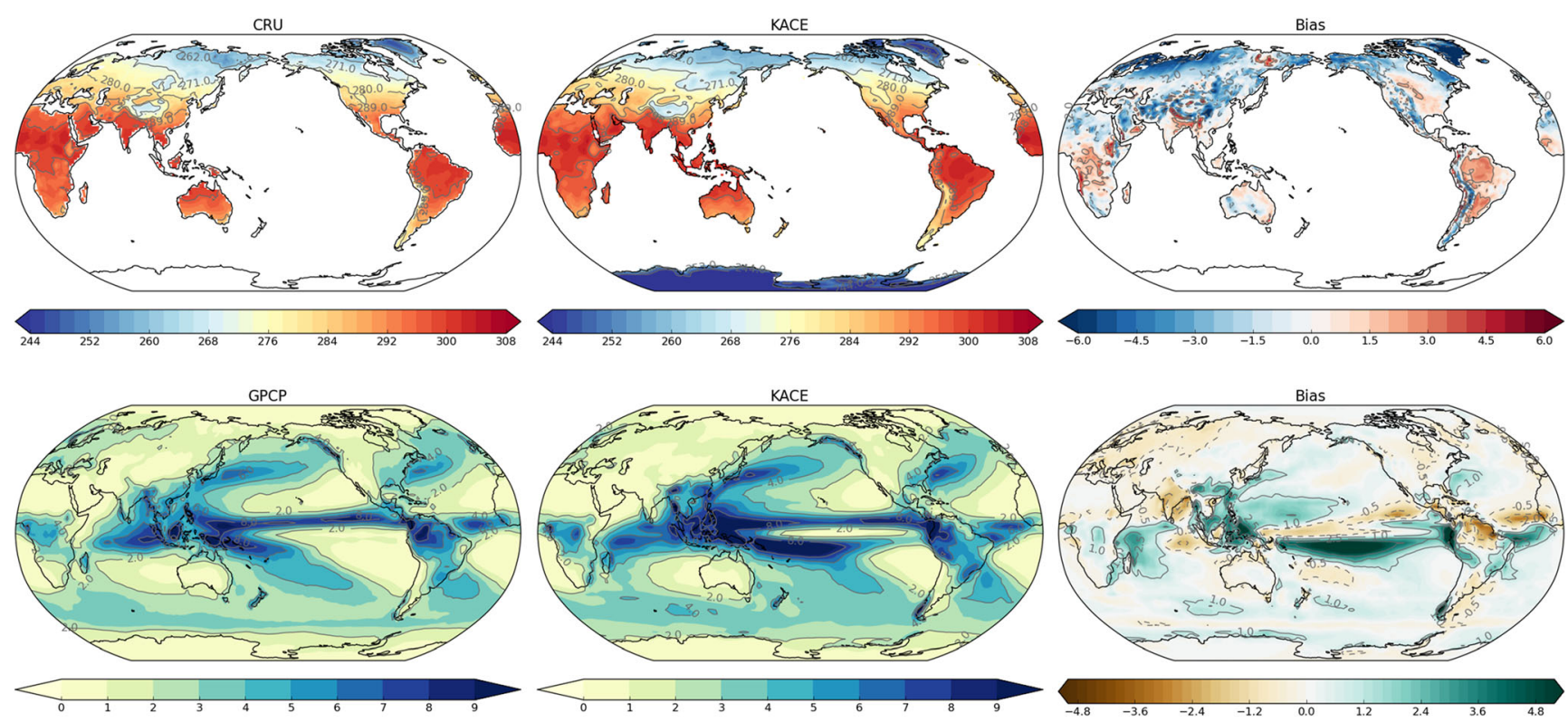

Fig. 5 Annual mean surface (2 m) air temperature (K) (upper panels) and precipitation (mm/day) (lower panels) for 1996-2015: observation (CRU, GPCP; left), K-ACE (center), and bias (right) 


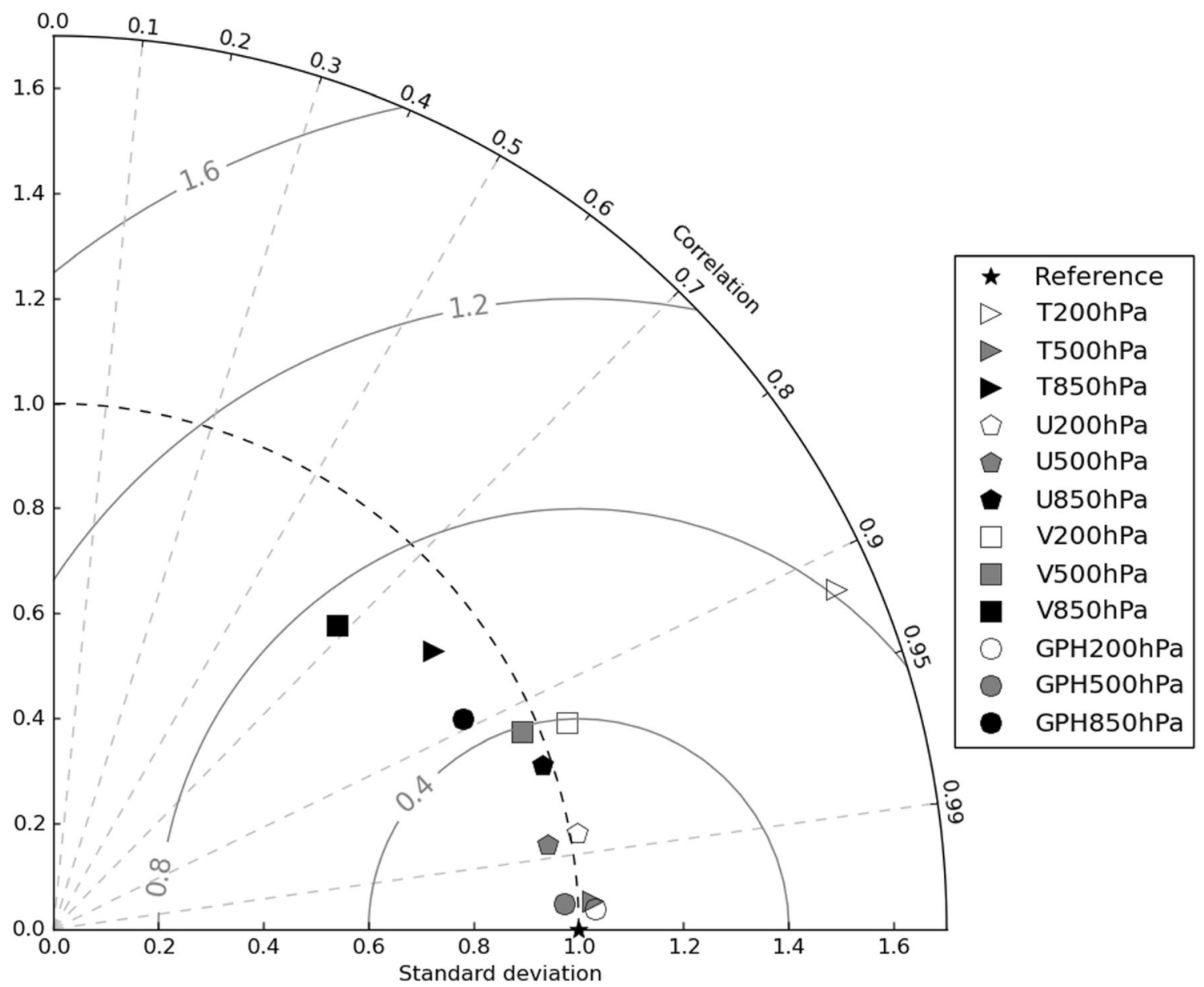

Fig. 6 Taylor diagram of the pressure-level variables for global fields from K-ACE. Black/Gray/White markers represent pressure level variables at 850, $500,200 \mathrm{hPa}$, respectively

problem in most coupled atmosphere-ocean models (Richer and Xie 2008). In contrast, most of the Southern Ocean shows warm biases.

\subsection{Comparison Against the CMIP5 Models}

To evaluate the performance of the K-ACE model relative to the CMIP5 models, the skill of the K-ACE mod$\mathrm{el}$, measured in terms of the pattern correlation between the observed and simulated fields, in simulating the key fields of the Earth system is compared with the corresponding skill of the CMIP5 models.

Figure 8 summarizes the pattern correlation between the simulated and observed in the K-ACE simulation (red) against the CMIP5 models (black). The performance of the K-ACE in simulating the spatial variations of the surface air temperature is similar to the CMIP5 model ensemble mean and is slightly below the CMIP5 model median. For precipitation, the pattern correlation of the CMIP5 models has much more wide spread than
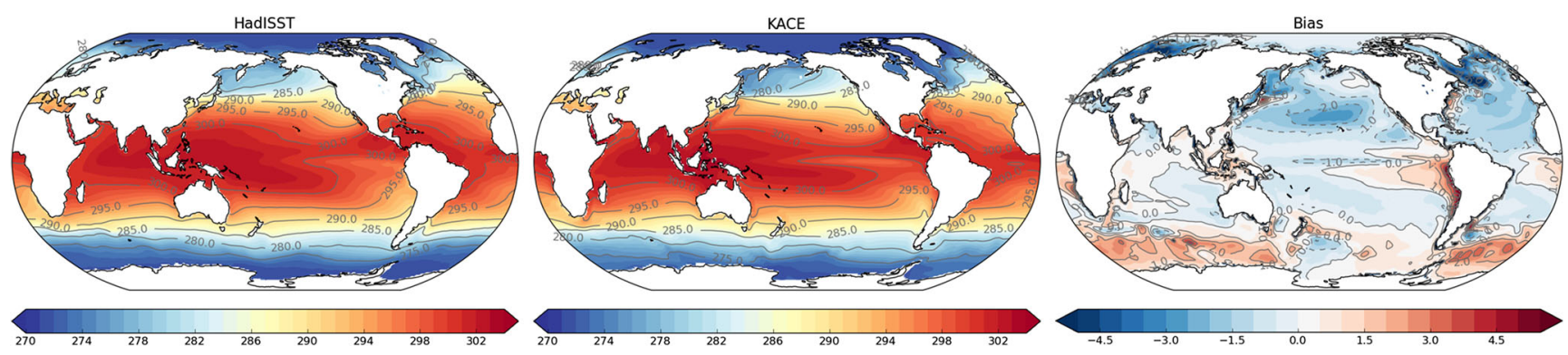

Fig. 7 Annual mean sea surface temperature (K) of the observation (left), K-ACE (center), and bias (right) to the period 1996-2015 
Fig. 8 Pattern correlations between simulated and observed annual mean climatology for the period 1996 to 2005 . The thick bold bars indicate the mean of CMIP5 models and the circle means median for CMIP5 models, while the red bars are for the K-ACE. On the $\mathrm{x}$-axis, TAS and PR mean $2 \mathrm{~m}$ air temperature and precipitation, respectively

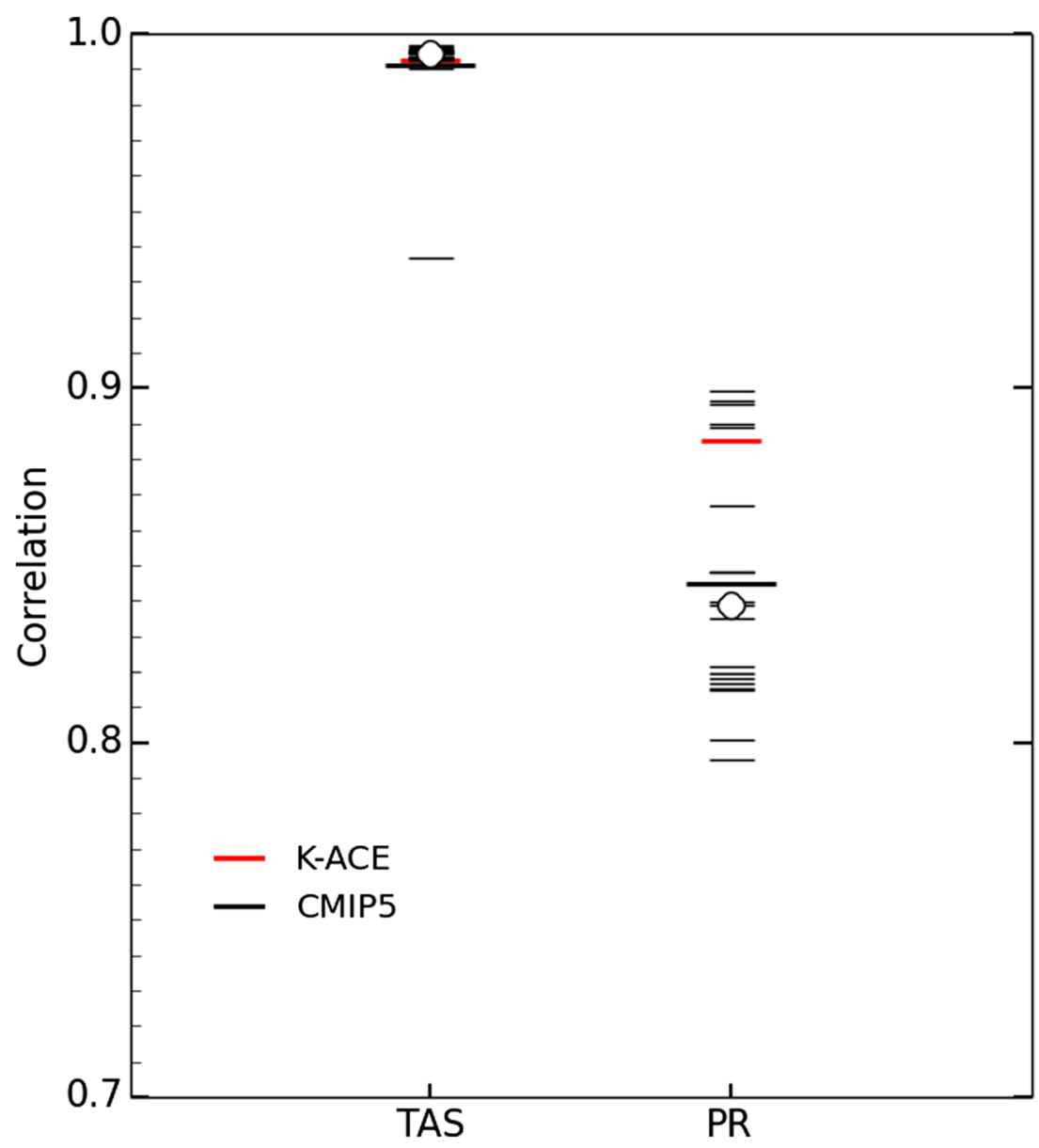

for the surface temperature. The K-ACE model outperforms most of the CMIP5 models with correlation higher than the ensemble-mean and the median of the CMIP5 models.

Additionally, the performance index given in Reichler and Kim (2008) which are composed with aggregated and normalized errors in 30 different key climate quantities (Table 6). The base period for the observations is 1990-2005 and the model data is compared against the present-day climate. To determine this index (performance index) for the K-ACE model, normalized error variance $E_{m}^{2}$ was calculated for each model in first step. The equation given below:

$E_{m}^{2}=\sum_{n=1}^{N} \frac{\left(\overline{S_{n}}-\overline{O_{n}}\right)^{2}}{\sigma_{n}{ }^{2}}$

Where, $\overline{S_{n}}$ is the simulated climatology for grid point $(n)$, the over bar indicates averaging, and the subscript " $\mathrm{m}$ " denotes each model. $\overline{O_{n}}$ is the observed climatology and $\sigma_{n}{ }^{2}$ is the inter-annual variance from the corresponding observations. Second, $E_{m}^{2}$ was scaled using ensemble to ensure the similar weight when combining their errors. The scaled equation as follows:

$I_{m}^{2}=\frac{E_{m}^{2}}{\overline{E_{E n s}^{2}}}$

The ensemble used in scaling is the present-day CMIP5 experiment. The final model performance index $\left(I^{2}\right)$ of the comparison between the K-ACE and the 29 CMIP5 models is presented in Fig. 9. A small value of index implies that the K-ACE model is closer to the observations for the corresponding variable. 17 climate variables in the evaluation of K-ACE simulation show medians below the 29 CMIP5 models; some climate variables (CLT, RSDS, RSUT, CRFST, V200, T200, PR, TAUU and TAUV) are much better simulated to be within the top $25 \%$ of the CMIP5 models. Moreover, the standard deviation of climate variables simulated by $\mathrm{K}-\mathrm{ACE}$ is within the range of CMIP5 ensembles (not shown). This means that the $\mathrm{K}$-ACE performance is comparable with CMIP5 model ensembles. 
Table 6 Climate variables and corresponding validation data. Those listed as 'global' or 'ocean' are single-level fields over their respective regions

\begin{tabular}{|c|c|c|c|}
\hline Variable & Domain & Acronym & Validation data \\
\hline $2 \mathrm{~m}$ air temperature & global & TAS & CRU, ICOADS, NOAA \\
\hline Total cloudiness & global & CLT & CERES \\
\hline Surface downwelling shortwave flux in air & global & RSDS & CERES \\
\hline Surface upwelling shortwave flux in air & global & RSUS & CERES \\
\hline Surface downwelling longwave flux in air & global & RLDS & CERES \\
\hline Surface upwelling longwave flux in air & global & RLUS & CERES \\
\hline TOA outgoing shortwave flux & global & RSUT & CERES \\
\hline TOA outgoing longwave flux & global & RLUT & CERES \\
\hline TOA cloud radiative forcing longwave flux & global & CRFLT & CERES \\
\hline TOA cloud radiative forcing shortwave flux & global & CRFST & CERES \\
\hline Precipitation & global & PR & CMAP, GPCP \\
\hline Precipitable water & global & PRW & HOAPS3 \\
\hline Sea surface temperature & ocean & TOS & HadISST, SODA \\
\hline Surface downward zonal stress & ocean & TAUU & ICOADS \\
\hline Surface downward meridional stress & ocean & TAUV & ICOADS \\
\hline Sea level pressure & ocean & PSL & ERSLP, HADSLP, ICOADS \\
\hline Surface upward sensible heat flux & ocean & HFSS & $\begin{array}{l}\text { ICOADS, OAFLUX, GSSTFMC3, } \\
\text { HOAPS3, JOFURO }\end{array}$ \\
\hline Surface upward latent heat flux & ocean & HFLS & $\begin{array}{l}\text { ICOADS, OAFLUX, GSSTFMC3, } \\
\text { HOAPS3, JOFURO }\end{array}$ \\
\hline Sea surface height & ocean & ZOS & GODAS, SODA \\
\hline Sea surface salinity & ocean & SO & GODAS, SODA \\
\hline Surface skin temperature & land & $\mathrm{TS}$ & ERA-Interim \\
\hline $200 \mathrm{hPa}$ zonal wind & global & $\mathrm{U} 200$ & ERA-Interim \\
\hline $200 \mathrm{hPa}$ meridional wind & global & V200 & ERA-Interim \\
\hline $200 \mathrm{hPa}$ stream function & global & $\chi^{200}$ & ERA-Interim \\
\hline $200 \mathrm{hPa}$ velocity potential & global & $\psi 200$ & ERA-Interim \\
\hline $200 \mathrm{hPa}$ air temperature & global & $\mathrm{T} 200$ & ERA-Interim \\
\hline $500 \mathrm{hPa}$ geopotential height & global & $\mathrm{Z} 500$ & ERA-Interim \\
\hline $500 \mathrm{hPa}$ stationary waves & global & SW500 & ERA-Interim \\
\hline $850 \mathrm{hPa}$ zonal wind & global & U850 & ERA-Interim \\
\hline $850 \mathrm{hPa}$ meridional wind & global & V850 & ERA-Interim \\
\hline
\end{tabular}

\section{Summary and Discussion}

This paper provides a general description of the first generation of KMA coupled model and the preliminary evaluation results from a climatological run of the model for the present day. The coupling structure is based on the role of sea ice in the climate system. The coupled model consists of the UM atmosphere model with JULES land model, MOM4p1 ocean and CICE sea ice models. The models are coupled using the OASIS3-MCT coupler. The model is evaluated using its simulation over the last 20 years out of 80 years to acquire an equilibrium state.

The surface air temperatures are well simulated with biases less than $3 \mathrm{~K}$, except in the high latitudes. The simulated precipitation over the tropics captures the observed climatological characteristics well; however, a double ITCZ with an elongated southern branch that almost reaches the Central Pacific in the
Southern Hemisphere, which is very common in other CMIP5 models, is still present. The mid-latitude precipitation has a wet bias in the eastern Asian monsoon band and in the North Atlantic. The positive SST biases off the coast of Peru and Western Sahara is considered to indicate that the coupled model underestimates coastal upwelling.

The simulated geographic distribution of the TOA radiation fluxes generally agrees with the observations. However, large regional biases appeared, particularly in the high latitudes of the Southern Hemisphere, where Antarctic sea ice is prevalent throughout the year. The model underestimates the Antarctic sea ice cover and, as a result, underestimates albedo to overestimate net radiation. The large biases may be attributed to the warm bias in the SST and the formation of less sea ice over the Antarctic Ocean which results from complex interactions between the atmosphere, ocean, and sea ice models. 


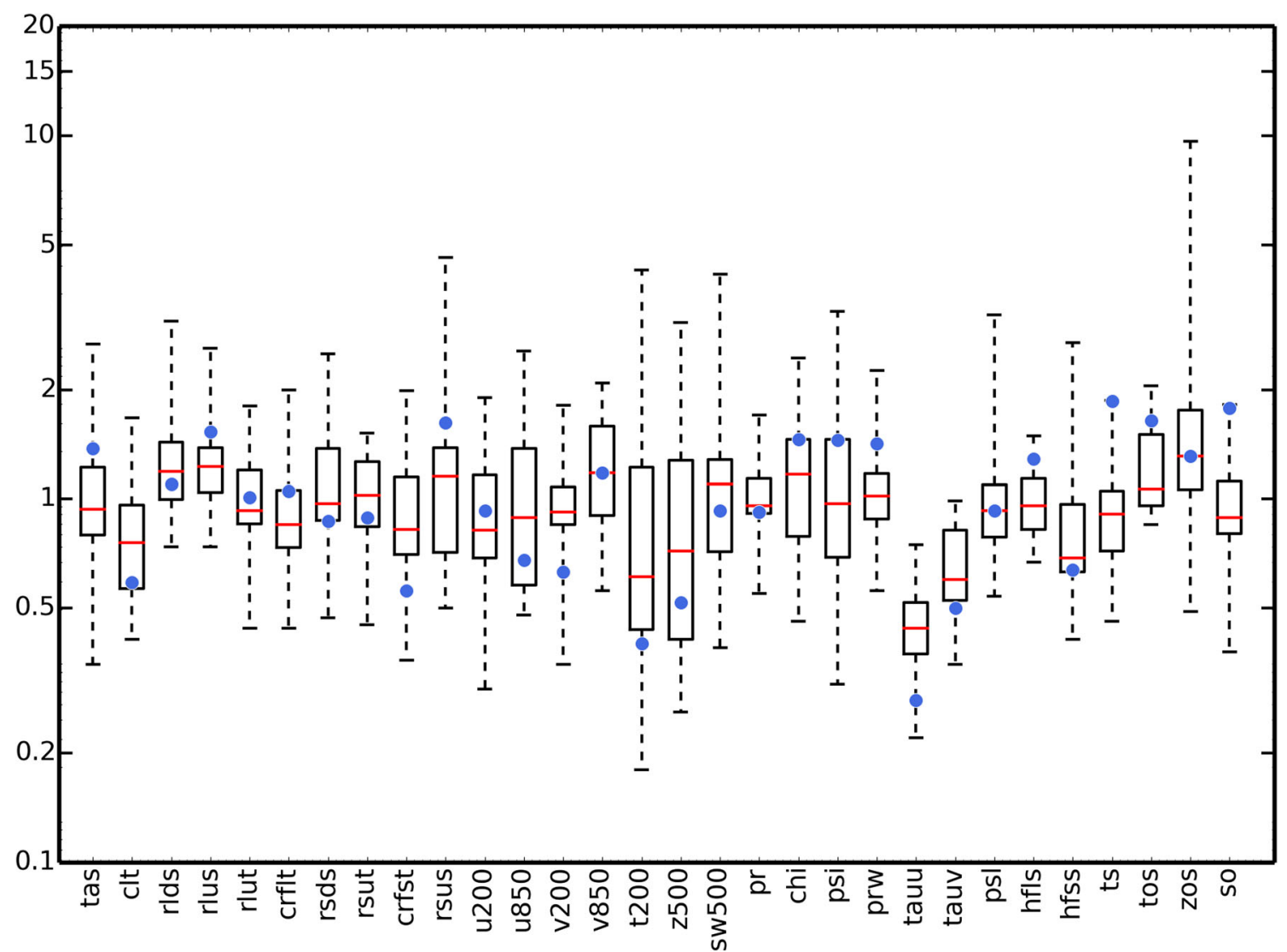

Fig. 9 The performance indexes of the K-ACE and CMIP5 models. The bars indicate the spread of the models, the boxes indicate a $25 \sim 75 \%$ performance for the 29 models. The red bars indicate the median values and the blue dots indicate values for the K-ACE model. On the $\mathrm{x}$-axis, chi and psi mean $\chi 200$ and $\psi 200$, respectively
Sea ice formation and maintenance is dependent on the SST. The cold (warm) bias in the Northern (Southern) Hemisphere resulted in overestimation (underestimation) of Arctic (Antarctic) sea ice. Although it has been reported that the negative sea ice bias in the Southern Hemisphere is common in the other CMIP5 models (Shu et al. 2015), the bias in the K-ACE simulation is even larger than other CMIP5 models. Therefore, research to identify the cause and improve the sea ice statistics is in progress. One of the possible ways to reduce this bias is to include Antarctic runoff (or ice shelf flux around Antarctica); this is expected to alleviate the overestimation by reducing the SST bias and altering the vertical structure of the ocean. Horizontal distributions and variability agree well with the observations for the surface and the pressure-level variables $(0.88-0.99$ and 0.69 0.99 , respectively). Performance of surface air temperatures and precipitation is similar to the CMIP5 model ensemble. In addition, trend of climate variability such as pacific decadal oscillation (PDO) is well represented in this research (not shown).

Thus, the first generation of the KMA coupled model is capable of capturing the average climatology and internal variability reasonably which are encouraging result behavior for a new model. Several deficiencies such as the biases in precipitation and SST in the tropics and Antarctic sea ice distributions are also identified in the evaluation work. Further work towards improving the performance of the model is in progress, and NIMS/KMA plans to contribute to CMIP6 using this model. Additionally, detail descriptions of climate variability in $\mathrm{K}$ ACE earth system model will be introduced in next research which shows historical and future scenario simulation results.

Acknowledgements This work was funded by the Korea Meteorological Administration Research and Development Program "Development and Assessment of IPCC AR6 Climate Change Scenarios" under Grant (1365003000).

Open Access This article is distributed under the terms of the Creative Commons Attribution 4.0 International License (http:// creativecommons.org/licenses/by/4.0/), which permits unrestricted use, distribution, and reproduction in any medium, provided you give appropriate credit to the original author(s) and the source, provide a link to the Creative Commons license, and indicate if changes were made.

\section{References}

Adler, R.F., Huffman, G.J., Chang, A., Ferraro, R., Xie, P., Janowiak, J., Rudolf, B., Schneider, U., Curtis, S., Bolvin, D., Gruber, A., Susskind, J., Arkin, P.: Ther version 2 global precipitation 
climatology project (GPCP) monthly precipitation analysis (1979present). J. Hydrometeorol. 4, 1147-1167 (2003)

Arakawa, A., Lamb, V.R.: Computational design of the basic dynamic processes of the UCLA general circulation model. Methods Comput. Phys. 17, 173-265 (1977)

Beckmann, A., Döscher, R.: A method for improved representation of dense water spreading over topography in geopotential-coordinate models. J. Phys. Oceanogr. 27, 581-591 (1997)

Bellouin, N., Rae, J., Jones, A., Johnson, C., Haywood, J., Boucher, O.: Aerosol forcing in the climate model Intercomparison project (CMIP5) simulations by HadGEM2-ES and the role of ammonium nitrate. J. Geophys. Res. 116, D20206 (2011)

Bellouin, N., Mann, G., Woodhouse, M.T., Johnson, C., Carslaw, K.S., Dalvi, M.: Impact of the modal aerosol scheme GLOMAP-mode on aerosol forcing in the Hadley Centre global environmental model. Atmos. Chem. Phys. 13, 3027-3044 (2013)

Best, M.J., Pryor, M., Clark, D.B., Rooney, G.G., Essery, R.L.H., Ménard, C.B., Edwards, J.M., Hendry, M.A., Porson, A., Gedney, N., Mercado, L.M., Sitch, S., Blyth, E., Boucher, O., Cox, P.M., Grimmond, C.S.B., Harding, R.J.: The joint UK land environment simulator (JULES), model description - part 1: energy and water fluxes. Geosci. Model Dev. 4, 677-699 (2011)

Bitz, C.M., Holland, M.M., Weaver, A.J., Eby, M.: Simulating the icethickness distribution in a coupled climate model. J. Geophys. Res. 106, 2441-2463 (2001)

Charney, J.G., Phillips, N.A.: Numerical integration of the quasigeostrophic equations for barotropic and simple baroclinic flows. J. meteor. 10, 71-99 (1953)

Clark, D.B., Mercado, L.M., Sitch, S., Jones, C.D., Gedney, N., Best, M.J., Pryor, M., Rooney, G.G., Essery, R.L.H., Blyth, E., Boucher, O., Harding, R.J., Huntingford, C., Cox, P.M.: The joint UK land environment simulator (JULES), model description - part 2: carbon fluxes and vegetation dynamics. Geosci. Model Dev. 4, 701-722 (2011)

Craig, A., Valcke, S., Coquart, L.: Development and performance of a new version of the OASIS coupler, OASIS3-MCT_3.0. Geosci. Model Dev. 10, 3297-3308 (2017)

Dee, D.P., Uppala, S.M., Simmons, A.J., Berrisford, P., Poli, P., Kbayashi, S., Andrae, U., Balmaseda, M.A., Balsamo, G., Bauer, P., Bechtold, P., Beljaars, A.C.M., van de Berg, L., Bidlot, J., Bormann, N., Delsol, C., Dragani, R., Fuentes, M., Geer, A.J., Haimberger, L., Healy, S.B., Hersbach, H., Holm, E.V., Isaksen, L., Kallberg, P., Kohler, M., Matricardi, M., McNally, A.P., Monge-Sanz, B.M., Morcrette, J.-J., Park, B.-K., Peubey, C., de Rosnay, P., Tavolato, C., Thepaut, J.-N., Vitart, F.: The ERA-interim reanalysis: configuration and performance of the data assimilation system. Q.J.R. Meteorol. Soc. 137, 553-597 (2011). https://doi.org/10.1002/qj.828

Döscher, R., Beckmann, A.: Effects of a bottom boundary layer parameterization in a coarse-resolution model of the North Atlantic Ocean. J. Atmos. Ocean. Tech. 17, 698-707 (1999)

Edwards, J.M., Slingo, A.: Studies with a flexible new radiation code. I: choosing a configuration for a large-scale model. Q. J. R. Meteorol. Soc. 122, 689-719 (1996)

Essery, R.L.H., Best, M.J., Betts, R.A., Cox, P.M., Taylor, C.M.: Explicit representation of subgrid heterogeneity in a GCM land surface scheme. J. Hydrometeorol. 4, 530-543 (2003)

FAO/IIASA/ISRIC/ISS-CAS/JRC: Harmonized world soil database (version 1.2), FAO, Rome, Italy and IIASA, Laxenburg, Austria (2009)

Flato, G.M.: Earth system models: an overview. WIREs Clim Change. 2, 783-800 (2011)

Fritsch, J.M., Chappell, C.F.: Numerical prediction of convectively driven mesoscale pressure systems. Part I: convective parameterization. J. Atmos. Sci. 37, 1722-1733 (1980)

Global Soil Data Task: Global soil data products CD-ROM (IGBP-DIS), CD-ROM, International Geosphere-Biosphere Programme, Data and Information System, Potsdam, Germany. Available from Oak
Ridge National Laboratory Distributed Active Archive Center, Oak Ridge, TN, https://daac.ornl.gov/SOILS/guides/igbp.html, last accessed: 25th October 2017 (2000)

Grant, A.L.M.: Cloud-base fluxes in the cumulus-capped boundary layer. Q. J. R. Meteorol. Soc. 127, 407-421 (2001)

Gregory, D., Rowntree, P.R.: A mass flux convection scheme with representation of cloud ensemble characteristics and stability dependent 20 closure. Mon. Wea. Rev. 118, 1483-1506 (1990)

Griffies, S.M., Hallberg, R.W.: Biharmonic friction with a Smagorinsky viscosity for use in large-scale eddy-permitting ocean models. Mon. Wea. Rev. 128, 2935-2946 (2000)

Griffies, S.M., Biastoch, A., Boning, C., Bryan, F., Dadabasoglu, G., Chassignet, E.P., England, M.H., Gerdes, R., Haak, H., Hallberg, R.W., Haeleger, W., Jungclaus, J., Large, W.G., Madec, G., Pirani, A., Saumels, B.L., Scheinert, M., Gupta, A.S., Severijns, C.A., Simmons, H.L., Treguier, A.M., Winton, M., Yeager, S., Yin, J.: Coordinated Ocean-ice reference experiments (COREs). Ocean Mode. 26, 1-46 (2009)

Griffies, S.M., Harrison, M.J., Pacanowski, R.C., Rosati, A.: A Technical Guide to MOM, GFDL Ocean Group Technical Report No. 5, NOAA/Geophysical Fluid Dynamics laboratory (2007)

Griffies, S.M., Winton, M., Donner, L.J., Horowitz, L.W., Downes, S.M., Farneti, R., Gnanadesikan, A., Hurlin, W.J., Lee, H.C., Liang, Z., Palter, J.B., Samuels, B.L., Wittenberg, A.T., Wyman, B.L., Yin, J., Zadeh, N.: The GFDL CM3 coupled climate model: characteristics of the ocean and sea ice simulations. J. Climate. 24, 3520-3544 (2011)

Hansen, J., Nazarenko, L., Ruedy, R., Sato, M., Willish, J., Genio, A.D., Koch, D., Lacis, A., Lo, K., Menon, S., Novakov, T., Perlwitz, J., Russell, G., Schmidt, G.A., Tausnev, N.: Earth's energy imbalance: confirmation and implications. Science. 308, 1431-1435 (2005)

Harris, I., Jones, P.D., Osborn, T.J., Lister, D.H.: Updated high-resolution grids of monthly climatic observations. Int. J. Climatol. 34, 623-642 (2014)

Hewitt, H.T., Copsey, D., Culverwell, I.D., Harris, C.M., Hill, R.S.R., Keen, A.B., McLaren, A.J., Hunke, E.C.: Design and implementation of the infrastructure of HadGEM3: the next-generation met Office climate modelling system. Geosci. Model Dev. 4, 223-253 (2011)

Hunke, E. C., Lipscomb, W. H., Turner, A. K., Jeffery, N., and Elliott, S.: CICE: the Los Alamos Sea Ice Model Documentation and Software user's Manual, Techical Report, LA-CC-06-012, Los Alamos National Laboratory (2015)

IPCC: Summary for policymakers. In: climate change 2013: the physical science basis. Contribution of working group I to the fifth assessment report of IPCC the intergovernmental panel on climate change (eds. Stocker, T. F., Qin, D., Plattner, G.-K., Tignor, M. M. B., Allen, S. K., Boschung, J., Nauels, A., Xia, Y., Bex, V., Midgley, P. M.), Cambridge University press, Cambridege, United Kingdom and New York, NY, USA, 3-29 (2014)

Large, W.G., McWilliams, J.C., Doney, S.C.: Oceanic vertical mixing: A review and a model with a nonlocal boundary layer parameterization. Rev. Geophys. 32, 363-403 (1994)

Large, W.G., Danabasoglu, G., McWilliams, J.C., Gent, P.R., Bryan, F.O.: Equatorial circulation of a global ocean climate model with anisotropic horizontal viscosity. J. Phys. Oceanogr. 31, 518-536 (2001)

Lawrence, D., Hurtt, G., Arneth, A., Brovkin, V., Calvin, K., Jones, A., Jones, C., Lawrence, P., de Noblet-Ducoudre, N., Pongratz, J., Seneviratne, S., Shevliakova, E.: The Land Use Model Intercomparison Project (LUMIP) contribution to CMIP6: Rationale and experimental design. Geosci. Mod. Dev. 9, 2973 2998 (2016)

Lipscomb, W.H., Hunke, E.C.: Modeling Sea ice transport using incremental remapping. Mon. Wea. Rev. 132, 1341-1354 (2004) 
Lipscomb, W.H., Hunke, E.C., Maslowski, W., Jakacki, J.: Ridging, strength, and stability in high-resolution sea ice models. J. Geophys. Res. 112, C03S91 (2007)

Loeb, N.G., Wielicki, B.A., Doelling, D.R., Smith, G.L., Keyes, D.F., Kato, S., Manalo-Smith, N., Wong, T.: Toward optimal closure of the Earth's top-of-atmosphere radiation budget. J. Clim. 22, 748766 (2009)

Mann, G.W., Carslaw, K.S., Spracklen, D.V., Ridley, D.A., Manktelow, P.T., Chipperfield, M.P., Pickering, S.J., Johnson, C.E.: Description and evaluation of GLOMAP-mode: A modal global aerosol microphysics model for the UKCA composition-climate model. Geosci. Mod. Dev. 3, 519-551 (2010)

Meinshausen, M., Vogel, E., Nauels, A., Lorbacher, K., Meinshausen, N., Etheridge, D.M., Fraser, P.J., Montzka, S.A., Rayner, P.J., Trudinger, C.M., Krummel, P.B., Beyerle, U., Canadell, J.G., Daniel, J.S., Enting, I.G., Law, R.M., Lunder, C.R., O’Doherty, S., Prinn, R.G., Reimann, S., Rubino, M., Velders, G.J.M., Vollmer, M.K., Wang, R.H.J., Weiss, R.: Historical greenhouse gas concentrations for climate modeling (CMIP6). Geosci. Mod. Dev. 10, 2057-2116 (2017)

Mlynczak, P.E., Smith, G.L., Doelling, D.R.: The annual cycle of earth radiation budget from clouds and the Earth's radiant energy system (CERES) data. J. Appl. Meteor. Climatol. 50, 2490-2503 (2011)

Murray, R.J.: Explicit generation of orthogonal grids for ocean models. J. Comp. Phys. 126, 251-273 (1996)

Pongratz, J., Reick, C., Raddatz, T., Claussen, M.: A global land cover reconstruction AD 800 to 1992: technical description. Berichte zur Erdsystemforschung. 51, (2008)

Raschke, E., Ohmura, A., Rossow, W.B., Carlson, B.E., Zhang, Y.-C., Stubenrauch, C., Kottek, M., Wild, M.: Cloud effects on the radiation budget based on ISCCP data (1991 to 1995). Int. J. Climatol. 25, 1103-1125 (2005)

Rayner, N.A., Parker, D.E., Horton, E.B., Folland, C.K., Alexander, L.V., Rowell, D.P., Kent, E.C., Kaplan, A.: Global analysis of sea surface temperature, sea ice, and night marine air temperature since the late nineteenth century. J. Geophys. Res. 108, 4407 (2003)

Reichler, T., Kim, J.: How well do coupled models simulate today's climate? Bull. Amer. Meteor. Soc. 89, 303-311 (2008)

Richer, I., Xie, S.-P.: On the origin of equatorial Atlantic biases in coupled general circulation models. Clim. Dyn. 31, 587-598 (2008)

Rothman, L.S., Gordon, I.E., Babikov, Y., Barbe, A., Chris Benner, D., Bernath, P.F., Birk, M., Bizzocchi, L., Boudon, V., Brown, L.R., Campargue, A., Chance, K., Cohen, E.A., Coudert, L.H., Devi, V.M., Drouin, B.J., Fayt, A., Flaud, J.M., Gamache, R.R., Harrison, J.J., Hartmann, J.-M., Hill, C., Hodges, J.T., Jacquemart, D., Jolly, A., Lamouroux, A.J., Le Roy, R.J., Li, G., Long, D.A., Lyulin, O.M., Mackie, C.J., Massie, S.T., Mikhailenko, S., Müller, H.S.P., Naumenko, O.V., Nikitin, A.V., Orphal, J., Perevalov, V., Perrin, A., Polovtseva, E.R., Richard, C., Smith, M.A.H., Starikova, E., Sung, K., Tashkun, S., Tennyson, J., Toon, G.C., Tyuterev, V.G., Wagner, G.: The HITRAN2012 molecular spectroscopic database. J. Quant. Spectrosc. Radiat. Transf. 130, 4-50 (2013)

Sen Gupta, A., Muir, L.C., Brown, J.N., Phipps, S.J., Durack, P.J., Monselesen, D., Wijffels, S.E.: Climate drift in CMIP3 models. J. Clim. 25, 4621-4640 (2012)

Shu, Q., Song, Z., Qiao, F.: Assessment of sea ice simulations in the CMIP5 models. Cryosphere. 9, 399-409 (2015)

Smith, G.L., Wielicki, B.A., Barkstrom, B.R., Lee, R.B., Priestley, K.J., Charlock, T.P., Minnis, P., Kratz, D.P., Loeb, N., Young, D.F.: Clouds and earth radiant energy system: an overview. Ad. Space Sci. 33, 1125-1131 (2004)

Storkey, D., Blaker, A.T., Mathiot, P., Megann, A., Aksenov, Y., Blockley, E.W., Calvert, D., Gragam, T., Hewitt, H.T., Hyder, P., Kuhlbrodt, T., Rae, J.G.L., Sinha, B.: UK Global Ocean GO6 and GO7: a traceable hierarchy of model resolutions. Geosci. Model Dev. 11, 3187-3213 (2018)

Taylor, K.E.: Summarizing multiple aspects of model performance in a single diagram. J. Geophys. Res. 106, 7183-7192 (2001)

Thorndike, A.S., Rothrock, D.A., Maykut, G.A., Colony, R.: The thickness distribution of sea ice. J. Geophys. Res. 80, 4501-4513 (1975)

Trenberth, K.E., Fasullo, J.T., Kiehl, J.: Earth's global energy budget. Bull. Amer. Meteor. Soc. 90, 311-323 (2009)

Turner, J., Bracegirdle, T.J., Phillips, T., Marshall, G.J., Hosking, J.S.: An initial assessment of Antarctic Sea ice extent in the CMIP5 models. J. Clim. 26, 1473-1484 (2013)

Valcke, S., Craig, T., Coquart L.: OASIS3-MCT user guide, OASIS3MTC 2.0, technical report, $W N / C M G C / 13 / 17$, CERFACS, Toulouse, France (2013)

Valcke, S., Craig, T., Coquart L: OASIS3-MCT user guide, OASIS3MTC_3.0, technical report, $T R / C M G C / 15 / 38$, CERFACS No1875, Toulouse, France (2015)

Walters, D., Baran, A., Boutle, I., Brooks, M., Edwards, J., Furtado, K., Hill, P., Lock, A., Manners, J., Morcrette, C., Mulcahy, J., Sanchez, C., Smith, C., Stratton, R., Tennant, W., Tomassini, L., Van Weverberg, K., Vosper, S., Willett, M., Browse, J., Bushell, A., Dalvi, M., Essery, R., Gedney, N., Hardiman, S., Johnson, B., Johnson, C., Jones, A., Mann, G., Milton, S., Rumbold, H., Sellar, A., Ujiie, M., Whitall, M., Williams, K., Zerroukat, M.: The Met Office Unified Model Global Atmosphere 7.0/7.1 and JULES Global Land 7.0 configurations. Geosci. Mod. Dev. Discuss., in review. (2017)

Wood, N., Mason, P.J.: The pressure force induced by neutral, turbulent flow over hills. Q. J. R. Meteorol. Soc. 127, 759-777 (1993)

Wood, N., Staniforth, A., White, A., Allen, T., Diamantakis, M., Gross, M., Melvin, T., Smith, C., Vosper, S., Zerroukat, M., Thuburn, J.: An inherently mass-conserving semi-implicit semi-Lagrangian discretization of the deep-atmosphere global non-hydrostatic equations. Q. J. R. Meteorol. Soc. 140, 1505-1520 (2014)

Publisher's Note Springer Nature remains neutral with regard to jurisdictional claims in published maps and institutional affiliations. 